Rabaska

Revue d'ethnologie de l'Amérique française

\title{
Société internationale du réseau ÉCONOMUSÉE
}

\section{Cyril Simard}

Volume 2, 2004

URI : https://id.erudit.org/iderudit/201697ar

DOI : https://doi.org/10.7202/201697ar

Aller au sommaire du numéro

Éditeur(s)

Société québécoise d'ethnologie

ISSN

1703-7433 (imprimé)

1916-7350 (numérique)

Découvrir la revue

Citer ce document

Simard, C. (2004). Société internationale du réseau ÉCONOMUSÉE. Rabaska, 2 , 307-309. https://doi.org/10.7202/201697ar d'utilisation que vous pouvez consulter en ligne.

https://apropos.erudit.org/fr/usagers/politique-dutilisation/ 
Société internationale

du réseau ÉCONoMUSÉE

203, Grande-Allée Est

Québec (Québec) G1R 2H8
Téléphone : (418) 694-4466

Télécopieur : (418) 694-4410

Courriel : info@economusees.com

Toile : www.economusees.com

\section{Mission}

Créée en mai 1992 par Cyril Simard (architecte, designer et ethnologue, président-directeur général de la Société et titulaire de la Chaire UNESCO en patrimoine culturel de l'université Laval) sous le nom de Fondation des Économusées du Québec, l'organisme porte désormais le nom de Société internationale du réseau Économusée. Organisme privé, sans but lucratif, la Société a pour membres un groupe d'artisans qui partagent une vision commune sur la façon de mettre en valeur et de transmettre des savoir-faire traditionnels auprès du public en respectant un principe d'équilibre entre culture et économie.

La Société a pour mission de conserver, de développer et de mettre en valeur les métiers et les savoir-faire traditionnels en favorisant l'implantation d'un réseau d'économusées à travers le pays et ce, afin d'offrir au public un produit touristique et culturel de qualité. Elle s'engage par ailleurs à fournir des services techniques et professionnels à tous les membres du réseau. L'authenticité dans le savoir-faire de l'artisan, la qualité de sa production, l'accueil qu'il réserve au public et l'exactitude de l'information qui lui est offerte sont autant de valeurs privilégiées par la Société. L'équipe de base de la Société travaille en étroite collaboration avec l'artisan pour la transformation de son entreprise en économusée. 


\section{Le réseau Économusée}

Le terme économusée désigne une entreprise qui utilise pour sa production une technique ou un savoir-faire traditionnel, ouvre ses portes au public en mettant en valeur ces savoir-faire, est dotée d'un lieu d'animation et d'interprétation de la production, dont la vente des produits finance complètement les opérations.

Dans chaque économusée, on retrouve les six mêmes composantes: l'accueil (lieu de bienvenue, fondement culturel de l'économusée), l'atelier de production et de création (transmission des savoir-faire par l'artisan), des collections anciennes (artéfacts et objets du passé, identité culturelle), des collections contemporaines (espace d'exposition d'œuvres contemporaines provenant d'autres artisans ou d'autres pays), le centre de documentation (livres, documents, vidéo traitant du métier, à consulter sur place), la boutique (lieu de vente des produits fabriqués par l'artisan).

Actuellement, le réseau comprend 36 économusées (29 au Québec et 7 dans les provinces de l'Atlantique), représentant des métiers traditionnels d'art et d'agro-alimentaire très différents tels que la lutherie, la fabrication du papier, la sculpture sur sable, la fourrure, la pomiculture, l'herboristerie, la brasserie, le salage et le séchage de la morue, etc. La gamme est variée, ce qui fait la richesse du réseau. Le visiteur, qu'il soit touriste, étudiant, connaisseur ou simplement curieux, aura envie d'explorer l'ensemble de ce réseau pour satisfaire sa soif de connaissance.

L'application du concept démontre à ce jour des impacts positifs sur le développement du tourisme culturel, sur la création d'emplois et sur la viabilité des entreprises. Ce métissage d'histoire, de patrimoine, de science et de technologie à vocation pédagogique fait l'intérêt des entreprises auprès des visiteurs d'ici et d'ailleurs. Le réseau est d'ailleurs en constante évolution et continue à se développer au pays, ayant acquis au cours des ans une renommée nationale et internationale (prospection en cours). Le certificat d'authenticité d'un produit Économusée est un label de qualité que le consommateur avisé recherche de plus en plus.

\section{Exposition}

Une série de timbres-poste « Mains de maître » a été émise par Postes Canada en avril 1999 et a obtenu le premier prix pour la qualité artistique de l'émission au Festival international de l'art philatélique, à Asagio, en Italie. Chacun des huit timbres illustre les mains d'un artisan du réseau à l'œuvre, évoquant ainsi la beauté des gestes associés au processus de création. Ces timbres ont fourni la matière première à une exposition itinérante intitulée «Des mains de maittre, l'expression contemporaine de métiers traditionnels ». Organisée par la Société internationale du réseau Économusée en collaboration avec le 
Musée canadien de la poste et le Musée canadien des civilisations, cette exposition rassemble, autour des huit timbres-poste de la série Métiers et savoir-faire, des œuvres anciennes et contemporaines créées par des artisans du réseau. Depuis 1999, elle parcourt les musées du Canada avec succès et son itinérance va se poursuivre jusqu'en 2006. L'itinéraire complet se trouve dans la brochure Économusée, Le Réseau 2004-2005.

\section{Publication}

Un ouvrage collectif, réunissant 60 auteurs de provenances diverses sous la direction de Cyril Simard, intitulé Des métiers...de la tradition à la création (415 pages), a paru en octobre 2003 : il s'agit d'une réflexion sur l'importance de la préservation des métiers et savoir-faire dans une perspective de création de produits nouveaux, adaptés au monde contemporain. La préface est signée par $\mathrm{M}^{\mathrm{me}}$ Sonia Ramzi, directrice du Patrimoine mondial à l'UNESCo. Cet ouvrage est en vente aux Éditions GID (pour commander - téléphone: (418) 877-3110 ou télécopie 877-3741).

\section{Autres outils d'information}

Outre sa brochure annuelle Économusée. Le Réseau 2004-2005, tirée à 125000 exemplaires et distribuée gratuitement dans les bureaux d'information touristique, les hôtels, les économusées eux-mêmes ou sur demande au siège de la Société, et les dépliants spécifiques de chaque membre du réseau, la Société publie un journal d'information semestriel Savoir-faire et faire savoir, destiné aux intervenants touristiques et aux divers organismes œuvrant dans le domaine de la culture ou de l'artisanat. En complément, le nouveau site, qui a été mis en ligne au cours de l'été 2004, offrira une information continuellement à jour sur le réseau électronique.

CYrIL SimARD 